\title{
Patent Ductus Arteriosus in Premature Neonates
}

\author{
Olachi J. Mezu-Ndubuisi ${ }^{1}$, Ghanshyam Agarwal ${ }^{2}$, Aarti Raghavan ${ }^{1}$, Jennifer T. Pham ${ }^{3}$, \\ Kirsten H. Ohler ${ }^{3}$, and Akhil Maheshwari ${ }^{1}$ \\ ${ }^{1}$ Division of Neonatology, Department of Pediatrics, University of Illinois at Chicago, $840 \mathrm{~S}$ Wood \\ St, CSB 1257, Chicago IL 60612 \\ ${ }^{2}$ Division of Neonatology, Department of Pediatrics, John H. Stroger Jr. Hospital of Cook County, \\ 1901 W Harrison, Chicago, IL 60612 \\ ${ }^{3}$ Department of Pharmacy Practice, University of Illinois at Chicago, 833 S Wood St, Room 164, \\ Chicago, IL 60612
}

\begin{abstract}
Persistent patency of the ductus arteriosus is a major cause of morbidity and mortality in premature infants. In infants born prior to 28 weeks of gestation, a hemodynamically-significant patent ductus arteriosus (PDA) can cause cardiovascular instability, exacerbate respiratory distress syndrome, prolong the need for assisted ventilation, and increase the risk of bronchopulmonary dysplasia, intraventricular hemorrhage, renal dysfunction, intraventricular hemorrhage, cerebral palsy, and mortality. In this article, we review the pathophysiology, clinical features, and assessment of hemodynamic significance, and provide a rigorous appraisal of the quality of evidence to support current medical and surgical management of PDA of prematurity. Cyclooxygenase inhibitors such as indomethacin and ibuprofen remain the mainstay of medical therapy for PDA, and can be used both for prophylaxis as well as rescue therapy to achieve PDA closure. Surgical ligation is also effective and is used in infants who do not respond to medical management. Although both medical and surgical treatment have proven efficacy in closing the ductus, both modalities are associated with significant adverse effects. Because the ductus does undergo spontaneous closure in some premature infants, improved and early identification of infants most likely to develop a symptomatic PDA could help in directing treatment to the at-risk infants and allow others to receive expectant management.
\end{abstract}

\section{Keywords}

ductus; cyclo-oxygenase; congestive cardiac failure; indomethacin; ibuprofen

\section{Introduction}

In the developing fetus, the pulmonary artery and the aortic arch are connected via the ductus arteriosus, a vascular shunt that diverts the right ventricular output away from the fetus's fluid-filled lungs and into the systemic circulation [1]. Whereas this ductal shunt

Correspondence: Akhil Maheshwari, MD, 840 South Wood St, Suite 1257; Chicago, Illinois 60612, Office: 312-355-3282; Fax: 312-355-5548, akhil1@uic.edu. 
closes spontaneously within a few hours of birth in full-term infants, this process is frequently delayed/ interrupted in premature infants and is associated with increased risk of clinical complications [2-5]. In this article, we review the clinical features and management of persistent patent ductus arteriosus (PDA) in premature infants.

\section{Epidemiology}

The incidence of persistent PDA correlates inversely with birth weight and gestational age, seen in about $30 \%$ of infants born with a birth weight less than 1500 grams, $40 \%$ of infants weighing 751-1000 grams, and more than 50\% of those weighing 501-750 grams [4, 6-8].

Although spontaneous ductal closure occurs eventually in nearly a third of extremely premature neonates, more than $60 \%$ of all preterm infants born prior to 28 weeks' gestation receive medical or surgical treatment to prevent complications associated with persistent PDA such as exacerbation of respiratory distress syndrome (RDS) [9-12], pulmonary hemorrhage [13, 14], prolonged use of assisted ventilation [15], bronchopulmonary dysplasia (BPD) [10, 12, 16-20], intraventricular hemorrhage (IVH)[10, 12, 21, 22], renal dysfunction [23], necrotizing enterocolitis (NEC) [10, 12, 24, 25], periventricular leukomalacia (PVL) [26], cerebral palsy [27], and mortality [18, 22, 24, 28-30].

\section{Pathophysiology of PDA}

The ductus arteriosus undergoes functional closure within a few hours after birth due to constriction of the medial smooth muscle layer. A more definitive anatomical closure occurs over the next several days with intimal remodeling and loss of smooth muscle cells from the media [31-33]. With the cessation of the ductal shunt between the systemic and pulmonary circulation, the right ventricular output is now no longer diverted to the aorta and flows directly into the pulmonary circulation. The consequent increase in venous return from the lungs raises the left atrial pressures, closing the other right to left shunt of fetal life across the foramen ovale in the inter-atrial septum. With the closure of these two right to left shunts, the pulmonary and systemic circuits carry equal volumes of blood flow in 'series' instead of the 'parallel' configuration of fetal life. Although the physiological mechanisms involved in ductal closure are still being elucidated, postnatal changes in the systemic and pulmonary vascular resistance, sudden increase in tissue oxygenation after birth, decreased levels of prostaglandins, and increased expression of endothelin and its cognate receptors are known to play an important role [31].

In premature infants, the normal process of ductal closure is often delayed or interrupted. Very low birth weight ( $<1500$ grams), acute perinatal stress, moderate-severe RDS with a need for assisted ventilation within 24 hours of birth, neonatal sepsis, and higher total fluid administration during the initial few days after birth are some of the factors associated with persistent PDA [16, 34, 35]. As the pulmonary vascular resistance falls after birth, blood is increasingly shunted away from the aorta into the pulmonary artery, resulting in pulmonary overcirculation with frequent exacerbation of lung disease and increased risk of pulmonary hemorrhage and BPD[9-20, 31]. Left-to-right ductal shunting can also 'steal' blood from the systemic circulation and reduce end-organ perfusion [36], placing the preterm infant at 
increased risk of complications such as renal dysfunction [23], NEC [10, 12, 24, 25], IVH and PVL [26].

\section{Clinical Manifestations and Diagnosis of PDA}

PDA can be 'asymptomatic' (where no heart murmur is detected), 'symptomatic' (associated with a murmur), 'hemodynamically non-significant' (no cardiovascular dysfunction), or 'hemodynamically-significant' (with cardiovascular dysfunction) [37]. Most infants with PDA have a characteristic systolic or systolo-diastolic murmur at the upper left sternal border [37]. A hemodynamically-significant PDA is frequently marked by additional clinical signs such as an active precordium, bounding pulses, wide pulse pressure [28], and radiological signs such as cardiomegaly, prominent pulmonary vascular markings, dilatation of the left atrium, and a horizontalized left main bronchus [6,37]. As the shunt size increases, the electrocardiogram may also show signs of left ventricular hypertrophy and left atrial enlargement [6]. To assess the hemodynamic impact of the PDA, a clinical cardiovascular distress (CVD) scoring system can be useful (Table 1) [38]. The CVD score evaluates five variables (heart rate, peripheral arterial pulses, precordial pulsations, duration of murmur, and cardiothoracic ratio on chest X-ray); a score $>3$ is strongly associated with a hemodynamically-significant PDA.

Echocardiography is the mainstay of diagnosis and assessment of PDA. It allows direct visual assessment of the ductus originating from the descending aorta distal to the left subclavian artery and connecting to the main pulmonary artery [34]. The ratio of the smallest ductal diameter to the ostium of the left PA (PDA:LPA ratio) is a useful indicator of the ductal size, where ratios of $\geq 1,0.5-1$, and $<0.5$ indicate a large, medium, and small PDA, respectively [39]. Doppler flow studies can confirm ductal patency and help assess the direction of ductal flow, cardiac anatomy, ventricular function, the ratio of estimated pulmonary to systemic blood flow [40], and pulmonary artery pressures [6]. Echocardiography can also be useful in predicting the clinical course; the ductal size on day 3-4 (PDA:LPA ratio) is a useful predictor of a hemodynamically-significant PDA, antedating the onset of clinical signs by up to 2-3 days [41].

Although no laboratory tests can reliably indicate the presence of a PDA, circulating levels of B-type natriuretic peptide (BNP), a hormone secreted by the ventricles under hemodynamic stress and congestive heart failure, can be both sensitive and specific for detecting a hemodynamically-significant PDA and for monitoring response to therapy [42, 43]. Plasma concentrations of BNP between 70 and $100 \mathrm{pg} / \mathrm{mL}$ have been used to determine a symptomatic PDA [34]. In a prospective blinded study, Sanjeev et al. showed that a cutoff of $72 \mathrm{pg} / \mathrm{mL}$ was useful as a screening tool for a hemodynamically-significant PDA [42]. BNP levels were higher in infants with a hemodynamically-significant PDA ( $\mathrm{n}=14)$ compared to those without ( $\mathrm{n}=15 ; 508.5 \pm 618.2 v s .59 .5 \pm 69.9 \mathrm{pg} / \mathrm{mL}, p<0.005)$, and concentrations decreased after successful medical/surgical treatment of PDA ( $\mathrm{n}=12 ; 404.9 \pm$ 159.2 to $25.1 \pm 4.1 \mathrm{pg} / \mathrm{mL}, p<0.03$ ) [42]. Further study is needed in larger cohorts to determine whether BNP levels in early neonatal period can help differentiate between candidates for expectant $v s$. aggressive management [34]. 


\section{Management of Neonatal PDA}

\section{Medical Treatment of PDA}

Medical management of PDA in a premature infant is comprised of fluid restriction, cyclooxygenase (COX) inhibitors such as indomethacin and ibuprofen lysine, and, occasionally, cautious use of diuretics in symptomatic infants $[44,45]$. COX inhibitors promote the constriction and eventual closure of the ductus [46] by inhibiting the synthesis and release of prostaglandins, which play a major role in maintaining ductal patency during fetal life [31]. While indomethacin has been the traditional 'drug of choice' for treatment of PDA, US Food and Drug Administration approved the use of ibuprofen lysine in April 2006 for closure of clinically-significant PDA in premature infants $<32$ weeks and weighing between 500-1500 grams. There has been considerable variability in the dosing regimens for the two drugs; Table 2 summarizes dosing regimens for indomethacin and ibuprofen lysine used for prophylactic and rescue therapy.

\section{Surgical Treatment of PDA}

Surgical ligation of a symptomatic PDA in preterm neonates is successful in closing the ductal shunt in $98-100 \%$ cases $[47,48]$. The procedure is generally well-tolerated and is considered by some as a preferred first line of treatment in preterm infants who are less likely to respond to indomethacin, such as those weighing less than 800 grams with a large left atrial-aortic root ratio on echocardiography [47-52]. Surgical ligation of a hemodynamically-significant PDA can improve hemodynamics, lung compliance, and reduce the duration of mechanical ventilation [53,54]. Offered as a prophylactic therapy, surgical ligation was effective in preventing NEC [relative risk (RR) $0.25,95 \%$ confidence interval (CI) $0.08-0.83 ; p=0.02$, number needed to treat (NNT) 5] but did not reduce mortality, severe IVH, BPD, or retinopathy of prematurity (ROP)[55]. Complications of PDA ligation include pneumothorax, hypothermia, intra-operative bleeding, phrenic nerve palsy, wound infection, vocal cord palsy and thoracic scoliosis [47, 56, 57].

\section{Medical vs. Surgical Therapy for PDA}

Although the efficacy of both COX inhibitors as well as surgery in ensuring ductal closure is well-established, a consensus on the choice of medical $v s$. surgical treatment remains elusive. Gersony et al. [58] compared clinical outcomes in 154 preterm infants who received either surgical ligation or medical treatment with COX inhibitors for a symptomatic PDA. There was no difference in mortality, BPD, bleeding, NEC, sepsis, renal insufficiency, or IVH. The surgical group had a higher incidence of pneumothorax [RR 2.68, 95\% CI 1.454.93; risk difference (RD) $0.25,95 \%$ CI 0.11-0.38; number needed to harm (NNH) 4, 95\% CI 3-9) and severe ROP (RR 3.80, 95\% CI 1.12-12.93; RD 0.11, 95\% CI 0.02-0.20; NNH 9, 95\% CI 5-50) compared to the indomethacin group.

Three recent observational studies have reported that infants receiving surgical ligation of PDA may be at increased risk of adverse outcomes such as chronic lung disease, ROP, and neurosensory impairment [59-61]. In some studies, surgical ligation was also associated with increased cardiorespiratory morbidity in the immediate post-operative period [59, 62]. Because of these concerns, surgical ligation is generally considered as a 'rescue' strategy in 
infants who have a contraindication to treatment with COX inhibitors or have failed medical therapy [28, 63]. In a study of 3,779 infants weighing less than 1500 grams, Lee et al. [64] noted that $28 \%$ of infants were treated for PDA. In this group, $75 \%$ were treated with indomethacin alone, $8 \%$ with surgical ligation alone, and $17 \%$ received both indomethacin and surgical ligation.

\section{Prophylactic vs. therapeutic use of indomethacin}

Randomized controlled trials (RCTs) of indomethacin for prophylaxis against IVH and PDA were first published in the 1980s. Indomethacin prophylaxis, which was primarily directed against IVH, effectively closed the ductus in about $70 \%$ and reduced the incidence of a symptomatic PDA by 50\% [65-67]. Fowlie et al.[12] reviewed 19 RCTs $(\mathrm{n}=2872)$ of prophylactic indomethacin in preterm infants $<37$ weeks and showed a reduction in the incidence of symptomatic PDA (RR $0.44,95 \%$ CI $0.38,0.50$ ) and the need for surgical ligation (RR $0.51,95 \%$ CI $0.37,0.71$. The benefit of prophylactic indomethacin in reducing pulmonary hemorrhage, a known association of PDA [13, 14], remains unclear. Data from Bandstra [68], Couser [69], and the TIPP study [70] showed no benefit despite reducing the incidence of symptomatic PDA. In a study published in abstract form only, Domanico et al. [71] reported a strong trend towards prevention of pulmonary hemorrhage (5/52 in treated group vs. 12/48 in control; RR 0.38, 95\% CI 0.15, 1.01). In a study of 1202 infants, Alfaleh et al. [72] noted that prophylactic indomethacin reduced the risk for serious pulmonary hemorrhage by $35 \%$ in the first week and by $23 \%$ over the course of NICU stay. Prophylactic indomethacin did not change respiratory outcomes or the incidence of pulmonary hemorrhage, gastrointestinal perforations, NEC, severe bleeding, or sepsis. Treated infants had a higher incidence of oliguria (RR 1.90; 95\% CI 1.45, 2.47) but did not have major renal impairment.

In an effort to restrict the use of indomethacin and limit the possibility of adverse effects to patients with greater chance of benefit, some studies have targeted infants with an asymptomatic PDA (instead of treating all premature infants prophylactically). In a metaanalysis [73] of 3 RCTs [74-76] ( $\mathrm{n}=97)$, indomethacin treatment of asymptomatic PDA ( $v s$. placebo/no intervention)reduced the frequency of symptomatic PDA (RR 0.36, 95\% CI 0.19, 0.68 ) and duration of supplemental oxygen (weighted mean difference $-12.5,95 \% \mathrm{CI}-23.8$, $-1.26)$. There was no evidence of effect on mortality, BPD, IVH, ROP, or the total duration of ventilation.

\section{Dosing regimens for indomethacin}

Several dosing regimens of indomethacin have been used for prophylaxis and treatment of PDA (Table 2). The most commonly used prophylactic regimen includes three intravenous doses of $0.1 \mathrm{mg} / \mathrm{kg}$ every 24 hours, whereas treatment usually involves an initial dose of 0.2 $\mathrm{mg} / \mathrm{kg}$ followed by 2 doses of $0.1-0.2 \mathrm{mg} / \mathrm{kg}$ every 12 hours [74-76]. In cases with no success with an initial course or if the ductus reopens after initial closure, a second course may successfully close the PDA in up to $44 \%$ cases [77]. The rate of clinical reopening of ductus may be higher in infants with a birth weight less than 1000 grams and if echocardiography shows residual luminal flow $[78,79]$. Although most clinicians will try 
more than one course of indomethacin before opting for surgical ligation, multiple courses have not been evaluated in controlled trials.

The choice of the 12-hour dosing intervals in indomethacin therapy is largely empirical. In a retrospective study, Rosito et al. [80] compared indomethacin infusions over a 4-hour period every 24 hours with a new regimen where indomethacin was now infused over 30 minutes at a 12-hour dosing interval. Although there was a trend towards a higher rate of PDA closure and a lower need for surgical ligation of the ductus with the 12-hour dosing regimen, the differences did not reach statistical significance. The study also did not evaluate for the frequency of adverse effects in the two treatment groups.

Several studies have evaluated continuous infusions of indomethacin as a strategy to minimize adverse effects. Yoshimoto et al. [81] administered prophylactic indomethacin (within 6 hours of life) in 30 infants born between 23 and 24 weeks gestation at a continuous infusion of $0.01 \mathrm{mg} / \mathrm{kg} /$ hour for 12 hours. None of the treated infants developed a symptomatic PDA, compared to $11 / 15$ controls $(p<0.001)$. There was no difference in mortality and early neonatal morbidities in the two groups. Similarly, in meta-analysis [82] of data from two trials $[76,83]$, there was no difference in the efficacy or safety of continuous $v s$. bolus infusion of indomethacin for treatment of PDA. The frequency of ductal reopening and of adverse effects such as oliguria, azotemia, IVH, NEC, or mortality was also similar between the two groups.

\section{Ibuprofen therapy for PDA}

In a study of 160 infants weighing less than 1000 grams with a clinically-symptomatic PDA, Richards et al. [5] showed that 70 (44\%) infants had PDA closure after a single course of ibuprofen, and 32/80 (40\%) following a second course. Infants born prior to 26 weeks of gestation $(\mathrm{n}=83)$ were less likely to respond after both the first $(27.7 \%$ vs. $63.6 \% ; p<0.001)$ or second ( $30.9 \%$ vs. $60.0 \% ; p=0.026)$ courses. In other studies, oral and intravenouslyadministered ibuprofen may achieve a similar efficacy in ductal closure. Gokmen et al. [84] randomized 102 infants born with a birth weight less than 1500 grams to receive either oral or intravenous ibuprofen for closure of PDA. All infants received an initial dose of 10 $\mathrm{mg} / \mathrm{kg}$, followed by $5 \mathrm{mg} / \mathrm{kg}$ at 24 and 48 hours. The investigators detected a higher rate of PDA closure in the oral ibuprofen group compared to intravenous ibuprofen group (84.6\% versus $62 \%)$ after the first course of the treatment $(p=0.01)$. Although clinical renal injury was not detected, infants receiving oral ibuprofen showed a rise in cystatin-C levels (a marker of renal function that reflects glomerular filtration rate better than serum creatinine) after treatment $(p=0.001)$, indicating that infants with borderline renal function may need careful monitoring. Infants receiving intravenous ibuprofen did not show these changes.

Ibuprofen has also been used for prophylaxis against PDA. Ohlsson et al. [46] performed meta-analysis on seven studies $(\mathrm{n}=931)$ comparing prophylactic ibuprofen with placebo/no intervention. Ibuprofen decreased the incidence of PDA [RR 0.36, 95\% CI 0.29, 00.46); RD $-0.27,95 \% \mathrm{CI}-0.32,-0.21$; NNT $4,95 \%$ CI 3,5 ) and reduced the need for surgical ligation. Results from two studies administering oral ibuprofen had similar results, but showed an increased risk of gastrointestinal bleeding (NNH 4, 95\% CI 2, 17) [85, 
86].Ibuprofen also negatively affected renal function. There was no difference in mortality, IVH, and BPD.

\section{Indomethacin vs. ibuprofen for treatment of PDA}

Jones et al. [87] reviewed evidence from 10 randomized trials to evaluate the effects of indomethacin or ibuprofen compared with placebo on PDA closure, morbidity, and mortality in preterm infants with an echocardiographically- or clinically-significant PDA beyond 24 hours after birth. Included studies [44, 58, 74-76, 88-97] compared intravenous indomethacin vs. intravenous ibuprofen (10 trials), intravenous indomethacin vs. placebo (9 trials), and intravenous ibuprofen vs. placebo (1 trial). Both intravenous indomethacin (RR $2.39,95 \%$ CI 2.05 to 2.78 ) and intravenous ibuprofen (RR 2.40, 95\% CI 2.03 to 2.84) closed a PDA more effectively than placebo. Other studies $[98,99]$ have shown a similar efficacy of the two drugs. The two drugs also have a similar failure rate for PDA closure, ranging between 0-50\%; Ohlsson et al. [100] performed a meta-analysis on data from 19 trials ( $\mathrm{n}=956$ infants) for failure rates after 1-3 doses of ibuprofen compared to indomethacin. They did not find a significant difference between the two groups (RR 0.94, 95\% CI 0.76-1.17; RD $-0.02,95 \% \mathrm{CI}-0.07$ to 0.04$)$.

\section{Adverse effects of indomethacin vs. ibuprofen during treatment of PDA}

Little et al. [79] reviewed the clinical course of 167 infants treated with indomethacin for a symptomatic PDA, and noted adverse effects in $73 \%$ patients. Indomethacin therapy was associated with thrombocytopenia (36\%), azotemia (31\%), sepsis $(30 \%)$, oliguria (25\%), hyponatremia (25\%), IVH (16\%), pulmonary interstitial emphysema (11\%), NEC (8\%), intestinal perforation (4\%), and bleeding (3\%).

In a systematic review of 19 studies $(n=956)$ comparing ibuprofen and indomethacin to placebo in preterm $<37$ weeks and $<2500 \mathrm{~g}$, Ohlsson et al. [100] detected reduced risk of developing NEC with ibuprofen (RR $0.68,95 \%$ CI $0.47-0.99$; RD -0.04 , 95\% CI -0.08 to $-0.00 ; p=0.04)$. The proportion of infants with oliguria was also significantly lower in the ibuprofen group (RR $0.28,95 \%$ CI $0.14,0.54$; RD $-0.09,95 \%$ CI $-0.14,-0.05$ ) than in those treated with indomethacin. Infants in the ibuprofen group also had lower serum/plasma creatinine levels 72 hours after initiation of treatment (weighted mean difference -4.70 $\mathrm{mmol} / \mathrm{L}, 95 \% \mathrm{CI}-8.88,-0.53)$. These differences in renal toxicity are consistent with physiological studies that show greater impairment of renal perfusion when exposed to indomethacin as compared to ibuprofen [91, 92, 101, 102]. There were no differences in infants treated with indomethacin or ibuprofen in bilirubin levels, IVH, NEC, ROP, sepsis, rate of surgical ligation, length of hospital stay, or mortality.

\section{Limitations of Pharmacotherapy for PDA}

Pharmacotherapy for PDA has been shown to be efficacious in achieving ductal closure but is associated with notable side effects. Studies evaluating COX inhibitors for treatment of neonatal PDA are frequently limited by small sample size and lack of precision, making it difficult to draw strong conclusions regarding dosing regimens, comparative efficacy, and safety profiles of the drugs. Although both COX inhibitors and surgery are highly effective 
in closing the ductus, the routine use of COX inhibitors in preterm infants is now being increasingly questioned: RCTs show little evidence of benefit when used for the treatment of PDA; prophylactic COX inhibitor therapy has not improved neurodevelopmental outcome; COX inhibitors are associated with significant side effects; and there is a high potential for spontaneous ductal closure [103-105]. The ductus may close spontaneously by postnatal day 8 in up to $40 \%$ of infants born with a birth weight less than 1000 grams [34].

\section{Conclusions}

Persistent patency of the ductus arteriosus is a major cause of morbidity and mortality in premature infants. Medical management of PDA in premature infants is comprised of fluid restriction and cyclo-oxygenase (COX) inhibitors such as indomethacin and ibuprofen lysine. In selected cases, surgical ligation of the ductus is also an option. There is a need for novel clinical/laboratory markers for early identification of infants at risk of developing a persistent and symptomatic PDA. Such an approach could potentially allow most premature infants to receive expectant management and limit active treatment to a few selected patients [103].

\section{Abbreviations}

WMD Weighted mean difference

RR Relative Risk

OR Odds Ratio

RD Risk Difference

CI Confidence Interval

NNT Number needed to treat

LPA Left Pulmonary Artery

CVD Cardiovascular Distress

RCT Randomized Controlled Trial

RDS Respiratory Distress Syndrome

NEC Necrotizing Enterocolitis

BPD Bronchopulmonary Dysplasia

IVH Intra-ventricular Hemorrhage

PVL Periventricular Leukomalacia

\section{References}

1. Hamrick SE, Hansmann G. Patent ductus arteriosus of the preterm infant. Pediatrics. 2010; 125(5): 1020-30. [PubMed: 20421261]

2. Yokoyama U, Minamisawa S, Ishikawa Y. Regulation of vascular tone and remodeling of the ductus arteriosus. J Smooth Muscle Res. 2010; 46(2):77-87. [PubMed: 20551589] 
3. Lemons JA, Bauer CR, Oh W, et al. Very low birth weight outcomes of the National Institute of Child health and human development neonatal research network, January 1995 through December 1996. NICHD Neonatal Research Network. Pediatrics. 2001; 107(1):E1.

4. Koch J, Hensley G, Roy L, et al. Prevalence of spontaneous closure of the ductus arteriosus in neonates at a birth weight of 1000 grams or less. Pediatrics. 2006; 117(4):1113-21. [PubMed: 16585305]

5. Richards J, Johnson A, Campbell M. A second course of ibuprofen is effective in the closure of a clinically significant PDA in ELBW infants. Pediatrics. 2009; 124(2):e287-93. [PubMed: 19651568]

6. Kozik DID, Ibrahim J, Wise-Faberowski L, et al. Patent Ductus Arteriosus. Critical Care of Children with Heart Disease. 2010; Chapter 14:145-157.

7. Furzan JA, Reisch J, Tyson JE, et al. Incidence and risk factors for symptomatic patent ductus arteriosus among inborn very-low-birth-weight infants. Early Hum Dev. 1985; 12(1):39-48. [PubMed: 4064996]

8. Mouzinho AI, Rosenfeld CR, Risser R. Symptomatic patent ductus arteriosus in very-low-birthweight infants: 1987-1989. Early Hum Dev. 1991; 27(1-2):65-77. [PubMed: 1802665]

9. Jones RW, Pickering D. Persistent ductus arteriosus complicating the respiratory distress syndrome. Arch Dis Child. 1977; 52(4):274-81. [PubMed: 324406]

10. Fowlie PW, Davis PG. Prophylactic indomethacin for preterm infants: a systematic review and meta-analysis. Arch Dis Child Fetal Neonatal Ed. 2003; 88(6):F464-6. [PubMed: 14602691]

11. Behman RE, Jacob J, Gluck L, et al. The contribution of PDA in the neonate with severe RDS. J Pediatr. 1980; 96(1):79-87. [PubMed: 6892514]

12. Fowlie PW, Davis PG, McGuire W. Prophylactic intravenous indomethacin for preventing mortality and morbidity in preterm infants. Cochrane Database Syst Rev. 2010; (7) CD000174.

13. Kluckow M, Evans N. Ductal shunting, high pulmonary blood flow, and pulmonary hemorrhage. The Journal of Pediatrics. 2000; 137(1):68-72. [PubMed: 10891824]

14. Finlay ER, Subhedar NV. Pulmonary haemorrhage in preterm infants. Eur J Pediatr. 2000; 159(11):870-1. [PubMed: 11079209]

15. Siassi B, Emmanouilides GC, Cleveland RJ, et al. Patent ductus arteriosus complicating prolonged assisted ventilation in respiratory distress syndrome. J Pediatr. 1969; 74(1):11-9. [PubMed: 4882539]

16. Oh W, Poindexter BB, Perritt R, et al. Association between fluid intake and weight loss during the first ten days of life and risk of bronchopulmonary dysplasia in extremely low birth weight infants. J Pediatr. 2005; 147(6):786-90. [PubMed: 16356432]

17. Redline RW, Wilson-Costello D, Hack M. Placental and other perinatal risk factors for chronic lung disease in very low birth weight infants. Pediatr Res. 2002; 52(5):713-9. [PubMed: 12409518]

18. Marshall DD, Kotelchuck M, Young TE, et al. Risk factors for chronic lung disease in the surfactant era: a North Carolina population-based study of very low birth weight infants. North Carolina Neonatologists Association. Pediatrics. 1999; 104(6):1345-50. [PubMed: 10585987]

19. Kitterman JA, Edmunds HL, Gregory GA, et al. Patent ducts arteriosus in premature infants. Incidence, relation to pulmonary disease and management. N Engl J Med. 1972; 287(10):473-7. [PubMed: 5048708]

20. Northway WH Jr. Rosan RC, Porter DY. Pulmonary disease following respirator therapy of hyaline-membrane disease. Bronchopulmonary dysplasia. N Engl J Med. 1967; 276(7):357-68. [PubMed: 5334613]

21. Dykes FD, Lazara A, Ahmann P, et al. Intraventricular hemorrhage: a prospective evaluation of etiopathogenesis. Pediatrics. 1980; 66(1):42-9. [PubMed: 7402791]

22. Evans N, Kluckow M. Early ductal shunting and intraventricular haemorrhage in ventilated preterm infants. Arch Dis Child Fetal Neonatal Ed. 1996; 75(3):F183-6. [PubMed: 8976684]

23. Vanpee M, Ergander U, Herin P, et al. Renal function in sick, very low-birth-weight infants. Acta Paediatr. 1993; 82(9):714-8. [PubMed: 8241664] 
24. Dollberg S, Lusky A, Reichman B. Patent ductus arteriosus, indomethacin and necrotizing enterocolitis in very low birth weight infants: a population-based study. J Pediatr Gastroenterol Nutr. 2005; 40(2):184-8. [PubMed: 15699694]

25. Ryder RW, Shelton JD, Guinan ME. Necrotizing enterocolitis: a prospective multicenter investigation. Am J Epidemiol. 1980; 112(1):113-23. [PubMed: 6772021]

26. Shortland DB, Gibson NA, Levene MI, et al. Patent ductus arteriosus and cerebral circulation in preterm infants. Dev Med Child Neurol. 1990; 32(5):386-93. [PubMed: 2354752]

27. Drougia A, Giapros V, Krallis N, et al. Incidence and risk factors for cerebral palsy in infants with perinatal problems: a 15-year review. Early Hum Dev. 2007; 83(8):541-7. [PubMed: 17188824]

28. Noori S, McCoy M, Friedlich P, et al. Failure of Ductus Arteriosus Closure Is Associated With Increased Mortality in Preterm Infants. Pediatrics. 2009; 123(1):e138-e144. [PubMed: 19117835]

29. Brooks J, Travadi J, Patole S, et al. Is surgical ligation of patent ductus arteriosus necessary? The Western Australian experience of conservative management. Archives of Disease in Childhood Fetal and Neonatal Edition. 2005; 90(3):F235-FF239. [PubMed: 15846015]

30. Rojas MA, Gonzalez A, Bancalari E, et al. Changing trends in the epidemiology and pathogenesis of neonatal chronic lung disease. J Pediatr. 1995; 126(4):605-10. [PubMed: 7699543]

31. Chiruvolu A, Jaleel MA. Pathophysiology of patent ductus arteriosus in premature neonates. Early Hum Dev. 2009; 85(3):143-6. [PubMed: 19223128]

32. Clyman RI. Mechanisms regulating the ductus arteriosus. Biol Neonate. 2006; 89(4):330-5. [PubMed: 16770073]

33. Heymann MA, Rudolph AM. Control of the ductus arteriosus. Physiol Rev. 1975; 55(1):62-78. [PubMed: 1088992]

34. Chiruvolu A, Punjwani P, Ramaciotti C. Clinical and echocardiographic diagnosis of patent ductus arteriosus in premature neonates. Early Hum Dev. 2009; 85(3):147-9. [PubMed: 19217224]

35. Cotton RB, Lindstrom DP, Stahlman MT. Early prediction of symptomatic patent ductus arteriosus from perinatal risk factors: a discriminant analysis model. Acta Paediatr Scand. 1981; 70(5):7237. [PubMed: 7324921]

36. Clyman RI. Ibuprofen and patent ductus arteriosus. N Engl J Med. 2000; 343(10):728-30. [PubMed: 10974138]

37. Yeh TF. Patent ductus arteriosus in preterm infants. HK J Paediatr. 1997; 2:9-17.

38. Yeh TF, Raval D, Luken J, et al. Clinical evaluation of premature infants with patent ductus arteriosus: a scoring system with echocardiogram, acid-base, and blood gas correlations. Crit Care Med. 1981; 9(9):655-7. [PubMed: 7273813]

39. Wald RM, Adatia I, Van Arsdell GS, et al. Relation of limiting ductal patency to survival in neonatal Ebstein's anomaly. Am J Cardiol. 2005; 96(6):851-6. [PubMed: 16169376]

40. Iyer P, Evans N. Re-evaluation of the left atrial to aortic root ratio as a marker of patent ductus arteriosus. Arch Dis Child Fetal Neonatal Ed. 1994; 70(2):F112-7. [PubMed: 8154903]

41. Ramos FG, Rosenfeld CR, Roy L, et al. Echocardiographic predictors of symptomatic patent ductus arteriosus in extremely-low-birth-weight preterm neonates. J Perinatol. 2010; 30(8):535-9. [PubMed: 20182434]

42. Sanjeev S, Pettersen M, Lua J, et al. Role of plasma B-type natriuretic peptide in screening for hemodynamically significant patent ductus arteriosus in preterm neonates. J Perinatol. 2005; 25(11):709-13. [PubMed: 16222347]

43. Choi BM, Lee KH, Eun LB, et al. Utility of rapid B-type natriuretic peptide assay for diagnosis of symptomatic patent ductus arteriosus in preterm infants. Pediatrics. 2005; 115(3):e255-61. [PubMed: 15687418]

44. Patel J, Roberts I, Azzopardi D, et al. Randomized double-blind controlled trial comparing the effects of ibuprofen with indomethacin on cerebral hemodynamics in preterm infants with patent ductus arteriosus. Pediatr Res. 2000; 47(1):36-42. [PubMed: 10625080]

45. Knight DB. The treatment of patent ductus arteriosus in preterm infants. A review and overview of randomized trials. Semin Neonatol. 2001; 6(1):63-73.

46. Ohlsson A, Shah SS. Ibuprofen for the prevention of patent ductus arteriosus in preterm and/or low birth weight infants. Cochrane Database Syst Rev. 2011; (7) CD004213. 
47. Koehne PS, Bein G, Alexi-Mekhishvili V, et al. Patent ductus arteriosus in very low birthweight infants: complications of pharmacological and surgical treatment. J Perinat Med. 2001; 29(4):32734. [PubMed: 11565202]

48. Palder SB, Schwartz MZ, Tyson KRT, et al. Management of patent ductus arteriosus: a comparison of operative v pharmacologic treatment. J Pediatr Surg. 1987; 22(12):1171-4. [PubMed: 3440906]

49. Pokharel R, Hisano K, Yasufuku M, et al. Ligation of medically refracted patent ductus arteriosus (PDA) in an extremely low body weight premature infant. Surg Today. 1998; 28(12):1290-4. [PubMed: 9872552]

50. Satur CR, Walker DR, Dickinson DF. Day case ligation of patent ductus arteriosus in preterm infants: a 10 year review. Arch Dis Child. 1991; 66(4):477-80. [PubMed: 1812843]

51. Chen KB, Cheng HC, Wu YL, et al. The anesthetic management of a preterm infant weighing 500 grams undergoing ligation of patent ductus arteriosus--a case report. Acta Anaesthesiol Sin. 1999; 37(2):89-92. [PubMed: 10410409]

52. Trus T, Winthrop AL, Pipe S, et al. Optimal management of patent ductus arteriosus in the neonate weighing less than 800 g. J Pediatr Surg. 1993; 28(9):1137-9. [PubMed: 8308678]

53. Naulty CM, Horn S, Conry J, et al. Improved lung compliance after ligation of patent ductus arteriosus in hyaline membrane disease. J Pediatr. 1978; 93(4):682-4. [PubMed: 702251]

54. Cotton RB, Stahlman MT, Kovar I, et al. Medical management of small preterm infants with symptomatic patent ductus arteriosus. J Pediatr. 1978; 92(3):467-73. [PubMed: 632994]

55. Mosalli R, Alfaleh K. Prophylactic surgical ligation of patent ductus arteriosus for prevention of mortality and morbidity in extremely low birth weight infants. Cochrane Database Syst Rev. 2008; (1) CD006181.

56. Mikhail M, Lee W, Toews W, et al. Surgical and medical experience with 734 premature infants with patient ductus arteriosus. J Thorac Cardiovasc Surg. 1982; 83(3):349-57. [PubMed: 7062747]

57. Zbar RI, Chen AH, Behrendt DM, et al. Incidence of vocal fold paralysis in infants undergoing ligation of patent ductus arteriosus. Ann Thorac Surg. 1996; 61(3):814-6. [PubMed: 8619698]

58. Gersony WM, Peckman GJ, Ellison RC, et al. Effects of indomethacin in premature infants with patent ductus arteriosus: results of a national collaborative study. J Pediatr. 1983; 102(6):895-906. [PubMed: 6343572]

59. Chorne N, Leonard C, Piecuch R, et al. Patent ductus arteriosus and its treatment as risk factors for neonatal and neurodevelopmental morbidity. Pediatrics. 2007; 119(6):1165-74. [PubMed: 17545385]

60. Kabra NS, Schmidt B, Roberts RS, et al. Neurosensory impairment after surgical closure of patent ductus arteriosus in extremely low birth weight infants: results from the Trial of Indomethacin Prophylaxis in Preterms. J Pediatr. 2007; 150(3):229-34. 234 e1. [PubMed: 17307535]

61. Raval MV, Laughon MM, Bose CL, et al. Patent ductus arteriosus ligation in premature infants: who really benefits, and at what cost? J Pediatr Surg. 2007; 42(1):69-75. discussion 75. [PubMed: 17208543]

62. Rao R, Bryowsky K, Mao K, et al. Gastrointestinal complications associated with ibuprofen therapy for patent ductus arteriosus. J Perinatol. 2011

63. Ohlsson A, Walia R, Shah S. Ibuprofen for the treatment of patent ductus arteriosus in preterm and/or low birth weight infants. Cochrane Database Syst Rev. 2008; (1) CD003481.

64. Lee SK, McMillan DD, Ohlsson A, et al. Variations in practice and outcomes in the Canadian NICU network: 1996-1997. Pediatrics. 2000; 106(5):1070-9. [PubMed: 11061777]

65. Sperandio M, Beedgen B, Feneberg R, et al. Effectiveness and side effects of an escalating, stepwise approach to indomethacin treatment for symptomatic patent ductus arteriosus in premature infants below 33 weeks of gestation. Pediatrics. 2005; 116(6):1361-6. [PubMed: 16322159]

66. Chorne N, Jegatheesan P, Lin E, et al. Risk factors for persistent ductus arteriosus patency during indomethacin treatment. J Pediatr. 2007; 151(6):629-34. [PubMed: 18035143]

67. Jegatheesan P, Ianus V, Buchh B, et al. Increased indomethacin dosing for persistent patent ductus arteriosus in preterm infants: a multicenter, randomized, controlled trial. J Pediatr. 2008; 153(2): 183-9. [PubMed: 18534218] 
68. Bandstra ES, Montalvo BM, Goldberg RN, et al. Prophylactic indomethacin for prevention of intraventricular hemorrhage in premature infants. Pediatrics. 1988; 82(4):533-42. [PubMed: 3174314]

69. Couser RJ, Ferrara B, Wright G, et al. Prophylactic indomethacin therapy in the first twenty-four hours of life for the prevention of patent ductus arteriosus in preterm infants treated prophylactically with surfactant in the delivery room. The Journal of pediatrics. 1996; 128(5 Pt 1): 631-7. [PubMed: 8627434]

70. Schmidt B, Davis P, Moddemann D, et al. Long-term effects of indomethacin prophylaxis in extremely-low-birth-weight infants. N Engl J Med. 2001; 344(26):1966-72. [PubMed: 11430325]

71. Domanico RS, Waldman JD, Lester LA, et al. Prophylactic indomethacin reduces the incidence of pulmonary hemorrhage and patent ductus arteriosus in surfactant-treated infants < 1250 grams. Pediatr Res. 1994; 35:331A.

72. Alfaleh K, Smyth JA, Roberts RS. Prevention and 18-Month Outcomes of Serious Pulmonary Hemorrhage in Extremely Low Birth Weight Infants: Results From the Trial of Indomethacin Prophylaxis in Preterms. Pediatrics. 2008; 121(2):e233-e238. [PubMed: 18245398]

73. Cooke L, Steer P, Woodgate P. Indomethacin for asymptomatic patent ductus arteriosus in preterm infants. Cochrane Database Syst Rev. 2003; (2) CD003745.

74. Mahony L, Carnero V, Brett C, et al. Prophylactic indomethacin therapy for patent ductus arteriosus in very-low-birth-weight infants. N Engl J Med. 1982; 306(9):506-10. [PubMed: 7035955]

75. Weesner KM, Dillard RG, Boyle RJ, et al. Prophylactic treatment of asymptomatic patent ductus arteriosus in premature infants with respiratory distress syndrome. South Med J. 1987; 80(6):7068. [PubMed: 3296225]

76. Hammerman C, Startes E, Komark K, et al. Failure of prophylactic indomethacin to improve the outcome of the very low birth weight infant. Dev Pharmacol Ther. 1987; 10(6):393-404. [PubMed: 3677969]

77. Keller RL, Clyman RI. Persistent Doppler flow predicts lack of response to multiple courses of indomethacin in premature infants with recurrent patent ductus arteriosus. Pediatrics. 2003; 112(3 Pt 1):583-7. [PubMed: 12949288]

78. Weiss H, Cooper B, Brook M, et al. Factors determining reopening of the ductus arteriosus after successful clinical closure with indomethacin. J Pediatr. 1995; 127(3):466-71. [PubMed: 7658282]

79. Little DC, Pratt TC, Blalock SE, et al. Patent ductus arteriosus in micropreemies and full-term infants: the relative merits of surgical ligation versus indomethacin treatment. J Pediatr Surg. 2003; 38(3):492-6. [PubMed: 12632374]

80. Rosito G, Sum K, Chorne N. Comparison of two neonatal indomethacin protocols: efficacy and outcome for patent ductus arteriosus closure. J Clin Pharm Ther. 2010; 35(5):589-92. [PubMed: 20831682]

81. Yoshimoto S, Sakai H, Ueda M, et al. Prophylactic indomethacin in extremely premature infants between 23 and 24 weeks gestation. Pediatr Int. 2010; 52(3):374-7. [PubMed: 19843236]

82. Gork AS, Ehrenkranz RA, Bracken MB. Continuous infusion versus intermittent bolus doses of indomethacin for patent ductus arteriosus closure in symptomatic preterm infants. Cochrane Database Syst Rev. 2008; (1) CD006071.

83. Christmann V, Liem KD, Semmekrot BA, et al. Changes in cerebral, renal and mesenteric blood flow velocity during continuous and bolus infusion of indomethacin. Acta paediatrica. 2002; 91(4):440-6. [PubMed: 12061361]

84. Gokmen T, Erdeve O, Altug N, et al. Efficacy and safety of oral versus intravenous ibuprofen in very low birth weight preterm infants with patent ductus arteriosus. J Pediatr. 2011; 158(4):549_ 554 e1. [PubMed: 21094951]

85. Sangtawesin C, Sangtawesin V, Lertsuthiwong W, et al. Prophylaxis of symptomatic patent ductus arteriosus with oral ibuprofen in very low birth weight infants. J Med Assoc Thai. 2008; 91(Suppl 3):S28-34. [PubMed: 19255990] 
86. Sangtawesin V, Sangtawesin C, Raksasinborisut C, et al. Oral ibuprofen prophylaxis for symptomatic patent ductus arteriosus of prematurity. Journal of the Medical Association of Thailand = Chotmaihet thangphaet. 2006; 89(3):314-21. [PubMed: 16696414]

87. Jones LJ, Craven PD, Attia J, et al. Network meta-analysis of indomethacin versus ibuprofen versus placebo for PDA in preterm infants. Arch Dis Child Fetal Neonatal Ed. 2010; 96(1):F4552. [PubMed: 20876595]

88. Adamska E, Helwich E, Rutkowaska M, et al. [Comparison of the efficacy of ibuprofen and indomethacin in the treatment of patent ductus arteriosus in prematurely born infants] (In Polish). Med Wieku Rozwoj. 2005; 9(3 Pt 1):335-54. [PubMed: 16547381]

89. Gimeno NA, Cano SA, Fernández GC. Ibuprofen versus indomethacin in the treatment of patent ductus arteriosus in preterm infants (In Spanish). An Pediatr (Barc). 2005; 63:212-8. [PubMed: 16219273]

90. Lago P, Bettiol T, Salvadori S, et al. Safety and efficacy of ibuprofen versus indomethacin in preterm infants treated for patent ductus arteriosus: a randomised controlled trial. Eur J Pediatr. 2002; 161(4):202-7. [PubMed: 12014386]

91. Mosca F, Bray M, Lattanzio M, et al. Comparative evaluation of the effects of indomethacin and ibuprofen on cerebral perfusion and oxygenation in preterm infants with patent ductus arteriosus. J Pediatr. 1997; 131(4):549-54. [PubMed: 9386657]

92. Pezzati M, Vangi V, Biagiotti R, et al. Effects of indomethacin and ibuprofen on mesenteric and renal blood flow in preterm infants with patent ductus arteriosus. The Journal of Pediatrics. 1999; 135(6):733-738. [PubMed: 10586177]

93. Plavka SP, Borek I, Biolek J, et al. Ibuprofen vs. indomethacin in the treatment of patent ductus arteriosus (PDA) in very premature neonates (English abstract). Pediatr Res. 2001; 49:375A.

94. Su PH, Chen JY, Su CM, et al. Comparison of ibuprofen and indomethacin therapy for patent ductus arteriosus in preterm infants. Pediatr Int. 2003; 45(6):665-70. [PubMed: 14651538]

95. Van Overmeire B, Smets K, Lecoutere D, et al. A comparison of ibuprofen and indomethacin for closure of patent ductus arteriosus. N Engl J Med. 2000; 343(10):674-81. [PubMed: 10974130]

96. Van Overmeire B, Follens I, Hartmann S, et al. Treatment of patent ductus arteriosus with ibuprofen. Arch Dis Child Fetal Neonatal Ed. 1997; 76:F179-84. [PubMed: 9175948]

97. Yeh TF, Luken JA, Thaji A, et al. Intravenous indomethacin therapy in premature infants with persistent ductus arteriosus--a double-blind controlled study. J Pediatr. 1981; 98(1):137-45. [PubMed: 7005415]

98. Katakam LI, Cotton MC, Goldberg RN, et al. Safety and Effectiveness of Indomethacin versus Ibuprofen for Treatment of Patent Ductus Arteriosus. Amer J Perinatol. 2010; 27(EFirst):425, 429. [PubMed: 20013605]

99. Linder N, Bello R, Hernandez A, et al. Treatment of patent ductus arteriosus: indomethacin or ibuprofen? Am J Perinatol. 2010; 27(5):399-404. [PubMed: 20013578]

100. Ohlsson A, Walia R, Shah SS. Ibuprofen for the treatment of patent ductus arteriosus in preterm and/or low birth weight infants. Cochrane database of systematic reviews. 2010; (4) CD003481.

101. Cherif A, Khrouf N, Jabnoun S, et al. Randomized pilot study comparing oral ibuprofen with intravenous ibuprofen in very low birth weight infants with patent ductus arteriosus. Pediatrics. 2008; 122(6):e1256-61. [PubMed: 19047225]

102. Chotigeat U, Jirapapa K, Layangkool T. A comparison of oral ibuprofen and intravenous indomethacin for closure of patent ductus arteriosus in preterm infants. J Med Assoc Thai. 2003; 86(Suppl 3):S563-9. [PubMed: 14700149]

103. Benitz WE. Treatment of persistent patent ductus arteriosus in preterm infants: time to accept the null hypothesis? J Perinatol. 2010; 30(4):241-52. [PubMed: 20182439]

104. Laughon MM, Simmons MA, BoseC L. Patency of the ductus arteriosus in the premature infant: is it pathologic? Should it be treated? Curr Opin Pediatr. 2004; 16(2):146-51. [PubMed: 15021192]

105. Noori S. Patent ductus arteriosus in the preterm infant: to treat or not to treat? J Perinatol. 2010; 30(Suppl):S31-7. [PubMed: 20877405]

Drugs. Author manuscript; available in PMC 2015 May 15. 
Table 1

Cardiovascular Distress Score (CVD) in Premature Infants with PDA [38]

\begin{tabular}{|l|l|l|l|}
\hline \multicolumn{2}{|l|}{ Parameter } & SCORE \\
\hline & $\mathbf{0}$ & $\mathbf{1}$ & $\mathbf{2}$ \\
\hline Heart rate (bpm) & $<160$ & $160-180$ & $>180$ \\
\hline Heart murmur & None & Systolic murmur & Murmur continues to diastole \\
\hline Peripheral pulse & Normal & Bounding brachial & $\begin{array}{l}\text { Bounding brachial and dorsal } \\
\text { pedis }\end{array}$ \\
\hline Precordial pulsation & None & Palpable & Visible \\
\hline $\begin{array}{l}\text { Cardiothoracic } \\
\text { ratio }\end{array}$ & $<0.60$ & $0.60-0.65$ & $>0.65$ \\
\hline
\end{tabular}




\section{Table 2}

Pharmacotherapeutic Options for Neonatal PDA

\begin{tabular}{|c|c|}
\hline Drug & Dosing Regimen \\
\hline $\begin{array}{l}\text { Indomethacin Prophylaxis } \\
{[12,54,74-76]}\end{array}$ & $\begin{array}{l}\text { I. Short 3-dose course of prophylactic indomethacin }(0.2,0.1,0.1 \mathrm{mg} / \mathrm{kg} \text {, administered at } 24 \text {-hour } \\
\text { intervals) } \mathbf{O R} \\
\text { II. Extended 6-dose course }(0.2,0.1,0.1,0.1,0.1,0.1 \mathrm{mg} / \mathrm{kg} \text {, at } 24 \text {-hour intervals) starting within } 15 \\
\text { hours of birth OR } \\
\text { III. } 3 \text { dose course of } 0.1 \mathrm{mg} / \mathrm{kg} \mathrm{IV} \text { at } 24 \text {-hour intervals }\end{array}$ \\
\hline $\begin{array}{l}\text { Indomethacin Treatment } \\
\text { [100] }\end{array}$ & $\begin{array}{ll}\text { I. } & 1^{\text {st }} \text { dose: } 0.2-0.3 \mathrm{mg} / \mathrm{kg} \text { IV } \\
& 2^{\text {nd }} \text { dose: } 0.2 \mathrm{mg} / \mathrm{kg} \text { IV Q } 12-24 \text { hours after 1st dose if PDA persists } \\
& 3 \mathrm{rd} \text { dose: } 0.2 \mathrm{mg} / \mathrm{kg} \text { IV } 12-24 \text { hours after } 2 \text { nd dose if PDA persists OR } \\
\text { II. } & 0.2 \mathrm{mg} / \mathrm{kg} / \mathrm{dose} \mathrm{PO} / \mathrm{IV} \text { for three doses given at } 12 \text { hourly intervals }\end{array}$ \\
\hline Ibuprofen Prophylaxis [46] & I. Oral suspension $10 \mathrm{mg} / \mathrm{kg} ; 5 \mathrm{mg} / \mathrm{k}, 5 \mathrm{mg} / \mathrm{kg}$ PO q $24 \mathrm{hrs}$ for symptomatic PDA \\
\hline Ibuprofen Treatment $[5,84]$ & $\begin{array}{l}\text { I. Loading dose of } 10 \mathrm{mg} / \mathrm{kg} \mathrm{IV} / \mathrm{PO} \text { on day } 1 \text {, followed by } 5 \mathrm{mg} / \mathrm{kg} / \text { dose at } 24 \mathrm{hrs} \text { and } 48 \mathrm{hrs} \\
\text { subsequently OR } \\
\text { II. Oral ibuprofen } 10 \mathrm{mg} / \mathrm{kg} / \mathrm{dose} \text { for three doses given at } 24 \text { hourly intervals }\end{array}$ \\
\hline
\end{tabular}

